\title{
Recurrent pregnancy loss and metabolic syndrome
}

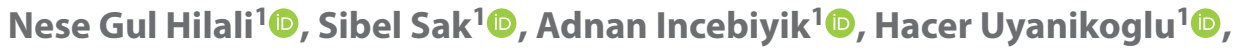 \\ Muhammet Erdal Sak ${ }^{1}$, Hatice Incebiyik ${ }^{3}{ }^{\mathbb{D}}$, Tevfik Sabuncu² ${ }^{\mathbb{C}}$ \\ ${ }^{1}$ Department of Obstetrics and Gynecology, University of Harran, School of Medicine, Sanliurfa, Turkey \\ ${ }^{2}$ Sanliurfa Eyyubiye Government Hospital, Sanliurfa, Turkey \\ ${ }^{3}$ Department of Endocrinology, University of Harran, School of Medicine, Sanliurfa, Turkey
}

\begin{abstract}
Objectives: The aim of this study was to evaluate the frequency of metabolic syndrome (MetS) and its components in patients with unexplained recurrent pregnancy loss (RPL).

Material and methods: A cross-sectional study was held including 115 patients with unexplained RPL who were referred to a tertiary center between December 2018 and December 2019. In the study, MetS was classified according to The National Cholesterol Education Program (NCEP) Adult Treatment Panel III (ATP III) criteria on the basis of metabolic risk factors. Frequency of MetS in the patients with unexplained RPL was investigated. The relationship between miscarriage rate and metabolic risk factors was also evaluated.

Results: According to our study the percentage of MetS in patients with unexplained RPL was $24.4 \%$. When evaluated according to different age groups, it was $18.4 \%$ in patients aged $20-29$ years, and it was $27.8 \%$ in patients aged $30-39$ years. At least having one of its components were high (82.6\%) in all patients with unexplained RPL.

Conclusions: The percentage of MetS or of at least having one of its components were high in patients with unexplained RPL. Increased number of having MetS components were associated with increased miscarriage rate.

Key words: recurrent pregnancy loss; miscarriage; metabolic syndrome; HDL; anticoagulant
\end{abstract}

Ginekologia Polska 2020; 91, 6: 320-323

\section{INTRODUCTION}

Pregnancy loss is the most common complication of pregnancy, and RPL is defined as two or more failed clinical pregnancies as documented with histopathologic examination or ultrasonography [1]. This problem affects $1 \%$ to $5 \%$ of all couples trying to conceive [2]. Causes of RPL have been attributed to either endocrine, genetic, structural, immune, or infective factors. In addition to these factors, the causes of almost half of the cases remain unexplained [3]. MetS is a pandemic health problem that includes some clinical findings such as hyperglycemia, dyslipidemia, abdominal obesity, and hypertension which are metabolic risk factors for both cardiovascular disease and type 2 diabetes [4]. It has been shown that rare complications of pregnancy such as preeclampsia, and small for gestational age infancy are variously associated with the MetS [5]. Hyperglycemia and hypertension, which are components of the MetS, can affect the vascular structure. Since the placenta is a vascular structure, any condition that may affect the vascular system may adversely affect the pregnancy outcomes. We suggest that MetS may be an etiological factor of unexplained RPL, hence we want to evaluate the frequency of MetS and its components in patients with RPL.

\section{MATERIAL AND METHODS}

This prospective cross-sectional study was conducted with a total of 115 patients with unexplained RPL who were referred to Harran University Hospital in Sanliurfa, Turkey, which is a tertiary referral center, between December 2018 and December 2019. The study was approved by the Local Institutional Research Ethics Board. The characteristics of patients were shown in Table 1. Inclusion criteria were patients who lost two or more consecutive pregnancies before the $20^{\text {th }}$ week of gestation with or without a previous live birth. All participants signed written informed consent prior to participating in the study. The clinical and obstetric history of participants was obtained. To investigate the etiology of RPL, all women were examined with a transvaginal ultrasound to identify congenital uterine abnormalities and intrauterine pathologies, and where necessary for confir- 
Table 1. Characteristics of patients recruited for the study

\begin{tabular}{|l|l|l|}
\hline & Mean & Min-Max \\
\hline Age [years] & $30.30 \pm 6.64$ & $18-45$ \\
\hline Gravidy & $5.35 \pm 2.41$ & $2-13$ \\
\hline Miscarriage rate & $3.28 \pm 1.39$ & $2-8$ \\
\hline Systolic blood pressure $[\mathrm{mm} \mathrm{Hg}]$ & $117.89 \pm 10.02$ & $100-170$ \\
\hline Diastolic blood pressure $[\mathrm{mm} \mathrm{Hg}]$ & $74.76 \pm 7.22$ & $55-90$ \\
\hline Body mass index [kg/m²] & $26.28 \pm 4.25$ & $19-42$ \\
\hline Waist circumference $[\mathrm{cm}]$ & $83.14 \pm 13.63$ & $56-120$ \\
\hline HDL- cholesterol $[\mathrm{mg} / \mathrm{dL}]$ & $50.03 \pm 12.89$ & $30-88$ \\
\hline Triglyceride $[\mathrm{mg} / \mathrm{dL}]$ & $129.97 \pm 75.99$ & $41-452$ \\
\hline Fasting glucose $[\mathrm{mg} / \mathrm{dL}]$ & $93.86 \pm 10.93$ & $75-125$ \\
\hline
\end{tabular}

Data were presented as mean \pm standart deviation

mation, patients underwent a sonohysterography. Blood samples of participants were taken to determine possible endocrinological reasons for RPL, such as thyroid disorders, diabetes mellitus (DM), and hyperprolactinemia. Anticardiolipin Ig $G$ and $M$, and levels of lupus anticoagulant were also evaluated to detect patients with Antiphospholipid Syndrome (APS). APS was diagnosed in accordance with the recommendations of international consensus criteria [6]. Maternal and paternal chromosome assessments were performed. In our clinic, these tests are routinely performed to clarify the etiology of RPL. The study was planned prospectively in order to avoid any problems regarding records of anthropometric measurements and tests. The study exclusion criteria included: Current pregnancy, smokers, alcohol consumption, maternal or paternal chromosome abnormalities, anatomical abnormalities, patients with APS, systemic diseases such as DM, hyperprolactinemia, thyroid dysfunction, chronic hypertension, systemic lupus erythematosus. Height, weight, waist circumference and blood pressure (BP) were measured by trained medical personnel. Body mass index (BMI) was calculated by weight $(\mathrm{kg})$ divided by the height $\left(\mathrm{m}^{2}\right)$. After 5 minutes of rest, arterial BP was measured on the right upper arm by a semiautomatic oscillometric device. Fasting glucose, high-density lipoprotein, and triglycerides were evaluated from blood as part of a overall health assessment. MetS was diagnosed based on The NCEP ATP III as the presence of any three of the following five traits: 1) Abdominal obesity, defined as a waist circumference $\geq 102 \mathrm{~cm}$ (40 in) in men and $\geq 88 \mathrm{~cm}$ (35 in) in women. 2) Serum triglycerides $\geq 150 \mathrm{mg} / \mathrm{dL}$ ( $1.7 \mathrm{mmol} / \mathrm{L}$ ) or drug treatment for elevated triglycerides. 3) Serum $\mathrm{HDL}-\mathrm{C}<40 \mathrm{mg} / \mathrm{dL}(1 \mathrm{mmol} / \mathrm{L})$ in men and $<50 \mathrm{mg} / \mathrm{dL}$ $(1.3 \mathrm{mmol} / \mathrm{L})$ in women or drug treatment for low HDL-C. 4) $\mathrm{BP} \geq 130 / 85 \mathrm{mmHg}$ or drug treatment for elevated $\mathrm{BP}$. 5) Fasting glucose $(\mathrm{FG}) \geq 100 \mathrm{mg} / \mathrm{dL}$ (5.6 mmol/L) or drug treatment for elevated blood glucose [7].

\section{Statistical analysis}

The Statistical Package for Social Sciences (SPSS 22.0; SPSS Inc., Chicago, IL) was used in all statistical analyses. Application of the Levene's test revealed that data distributions were normal. Results were expressed as means \pm standard deviations. Pearson correlation was done. The mean values of the the groups were analyzed using Independent Sample T Test. The values were calculated at level of $(p<0.05)$ significance.

\section{RESULTS}

Among the study group, the majority were in the age group of 30-39 years (54 patients, $47 \%$ ), followed by $20-$ -29years (49 patients, 42.6\%), 40-49 years (9 patients, 7.8\%) and the patients aged below than 20 years were minimum in number (3 patients, 2.6\%). The percentage of the MetS diagnosed using the ATP III criteria was $24.4 \%$ (28 of 115). The age adjusted percentage of MetS was calculated. It was $18.4 \%$ in the age group of $20-29$ years, and it was $27.8 \%$ in the age group of 30-39 years. There were 3 patients aged below 20 years, MetS was not seen in this group. There were 9 patients in the age group of 40-49 years. MetS was seen in four of them. Because of the low number, percentages were not calculated. There was a negative correlation between HDL-C levels and miscarriage rate $(r=-0.295, p<0.01)$. Hyperglycemia and age were also associated with miscarriage rate $(r=0.277, p<0.01 ; r=0.272, p<0.01$ respectively $)$. Additionally, an association had been seen between the presence of increased number of metabolic risk factors and miscarriage rate $(r=0.239, p<0.05)$. We found that $27.8 \%, 30.4 \%$, and $24.4 \%$ of the patients had at least 1,2 , or $\geq 3$ metabolic risk factors, respectively. At least one metabolic risk factor was seen in $82.6 \%$ of patients. The frequency of individual components of the MetS in patients with RPL are presented in Table 2. Low HDL-C and abdominal obesity were the most frequent components of the MetS in patients with RPL. Furthermore, patients were divided into two groups according to whether they had each metabolic risk factor or not, and evaluated in terms of miscarriage rate (Tab. 3). Low HDL-C group was associated with the increased miscarriage rate. It was statistically significant.

\section{DISCUSSION}

In this study we evaluated the percentage of MetS under the ATP III definition in the group of patients with unexplained RPL. We observed that the percentage of MetS or of at least having one of its components were high in these patients. Kozan et al. [8] studied the prevalence of the MetS in the adult Turkish population and they found that the prevalence was $9.6 \%$ in women aged $20-29$ years, and $29.7 \%$ in women aged 30-39 years. Soysal et al. [9] also studied the prevalence of MetS and its components among 
Table 2. Frequency of individual components of the MetS in patients with RPL

\begin{tabular}{|l|l|l|}
\hline All RPL Patients & Frequency & Percentage \\
\hline Hyperglycemia & $28 / 115$ & 24.35 \\
\hline Hypertriglyceridemia & $30 / 115$ & 26.09 \\
\hline $\begin{array}{l}\text { Abdominal obesity (Waist } \\
\text { circumference } \geq 88 \mathrm{~cm} \text { ) }\end{array}$ & $51 / 115$ & 44.35 \\
\hline Low HDL cholesterol & $67 / 115$ & 58.26 \\
\hline High blood pressure & $15 / 115$ & 13.04 \\
\hline RPL Patients with MetS & & \\
\hline & Frequency & Percentage \\
\hline Hyperglycemia & $17 / 28$ & 60.71 \\
\hline Hypertriglyceridemia & $19 / 28$ & 67.86 \\
\hline Abdominal obesity & $23 / 28$ & 82.14 \\
\hline Low HDL cholesterol & $26 / 28$ & 92.86 \\
\hline High blood pressure & $5 / 28$ & 17.86 \\
\hline
\end{tabular}

Table 3. The effects of presence of each metabolic risk factors on miscarriage rate

\begin{tabular}{|c|c|c|c|}
\hline & & Misscariage Rate & $\mathbf{p}^{*}$ \\
\hline HDL Cholesterol & $\begin{array}{l}<50 \mathrm{mg} / \mathrm{dL} \\
\geq 50 \mathrm{mg} / \mathrm{dL}\end{array}$ & $\begin{array}{l}3.59 \pm 1.51 \\
2.83 \pm 1.06\end{array}$ & $<0.01$ \\
\hline Triglyceride & $\begin{array}{l}\geq 150 \mathrm{mg} / \mathrm{dL} \\
<150 \mathrm{mg} / \mathrm{dL}\end{array}$ & $\begin{array}{l}3.17 \pm 1.45 \\
3.32 \pm 1.47\end{array}$ & $>0.05$ \\
\hline Fasting Glucose & $\begin{array}{l}\geq 100 \mathrm{mg} / \mathrm{dL} \\
<100 \mathrm{mg} / \mathrm{dL}\end{array}$ & $\begin{array}{l}3.64 \pm 1.68 \\
3.16 \pm 1.27\end{array}$ & $>0.05$ \\
\hline $\begin{array}{l}\text { Abdominal } \\
\text { Obesity }\end{array}$ & $\begin{array}{l}\geq 88 \mathrm{~cm} \\
<88 \mathrm{~cm}\end{array}$ & $\begin{array}{l}3.55 \pm 1.55 \\
3.06 \pm 1.21\end{array}$ & $>0.05$ \\
\hline $\begin{array}{l}\text { High Blood } \\
\text { Pressure }\end{array}$ & $\begin{array}{l}\geq 130 / 85 \mathrm{mmHg} \\
<130 / 85 \mathrm{mmHg}\end{array}$ & $\begin{array}{l}2.80 \pm 0.94 \\
3.35 \pm 1.43\end{array}$ & $>0.05$ \\
\hline
\end{tabular}

Data were presented as mean \pm standart deviation

*Independent Samples T Test

the young adults. They observed that the prevalence of MetS was $7.5 \%$ among 20 and 29 years old women and $24 \%$ among 30 and 39 years old women. It is known that MetS is more common in 30-39years old people than in 20-29years old people. Therefore, it is important to take notice that the percentage of MetS was 18.4\% in 20-29 years old group in our study. Withal, according to our knowledge this is the first study to evaluate the percentage of MetS in patients with unexplained RPL.

Our study also examined the relationship between each component of MetS and the miscarriage rate. The increased miscarriage rate was statistically significant in patients with low HDL-C. Kozan et al. [8] reported the most prevalent component of the MetS was abdominal obesity in women of Turkish adults, but we observed that low HDL-C was the most common component in our study. The percent- age of low HDL-C was $92.86 \%(26 / 28)$ in the patients with MetS with RPL, and it was $58.26 \%(67 / 115)$ in the whole group. As outlined previously, within the whole group there were 3 patients aged below 20 years. Although their ages were below 20 years, two of them had two metabolic risk factors. The first patient had abdominal obesity and low HDL-C. The other one had hyperglycemia and low HDL-C. The common metabolic risk factor was low HDL-C. It is important to remember that low HDL-C is associated with vascular endothelial dysfunction [10]. Although the number of patients is statistically insignificant, we suggest that low HDL-C may predict the early onset of events affecting the vascular structure, therefore it may be an early sign of poor pregnancy outcomes including unexplained RPL.

In the literature, there are studies about the MetS and adverse pregnancy outcomes, Hooijschuur et al. [5] suggested that different clinical manifestations of placental syndromes such as preeclampsia and small for gestational age infancy are variously associated with MetS. Murphy et al. [11] reported that risk ratios and prevalence rates for MetS increased in preeclamptic women at 1 year and 3 years after birth. All components of MetS are associated with oxidative stress, inflammation, and endothelial dysfunction [12], withal $82.6 \%$ of patients in our study have one or more metabolic risk factors. Fortunately, endothelial dysfunction is reversible, and treating metabolic risk factors such as hypercholesterolemia and hypertension results in improved endothelial function resulting in restoration of vascular function. New guidelines lower the definition of high blood pressure, and it is accepted as $\geq 130 / 80 \mathrm{mmHg}$, in order to prevent negative outcomes of hypertension [13]. Therefore, regulating the tension below $130 / 80 \mathrm{mmHg}$ may be appropriate for patients with unexplained RPL.

Pregnancy is a procoagulant state, and MetS is associated with idiopathic venous thromboembolism [14], therefore patients with MetS are at high risk of developing thromboembolic disorders during pregnancy [15]. In cases of MetS, anticoagulant therapy from the time of conception may have beneficial effects in these patients. Published data specific to the use of anticoagulant agents in pregnant patients with MetS are needed. MetS is also associated with higher proinflammatory mediators, and heparin has a variety of antiinflammatory potentials. Therefore, some pregnancy complications including unexplained RPL may benefit from anticoagulant therapy such as heparinoids [16]. Although the anticoagulant therapy is not recommended in patients with unexplained $\operatorname{RPL}[17,18]$, we suggest that using anticoagulant therapy may be useful because of high percentage of MetS in these patients, both for treatment and prevention of thromboembolic disorders. Evaluation of these patients only through the window of obstetrics may be insufficient, so a multidisciplinary team approach may be 
suitable. Healthier lifestyle changes, treating hypercholesterolemia, treating hypertension according to ACC/AHA [13], and anticoagulant therapy may be appropriate for patients with unexplained RPL. This study has some limitations. It has a cross sectional design, and the sample size of the study is low and data were obtained from a single center. Multi-center studies with more patients may be useful to advance this area of research.

In conclusion, this study may be significant for many reasons. First, MetS and related conditions may play a role in the etiology of unexplained RPL, therefore treating metabolic risk factors may benefit pregnancy outcomes. Secondly, it may be possible to raise awareness of these patients in terms of early cardiovascular risk factors that may occur in the future, thus preventing future complications.

\section{REFERENCES}

1. Definitions of infertility and recurrent pregnancy loss: a committee opinion. Fertility and Sterility. 2013; 99(1): 63, doi: 10.1016/j.fertnstert.2012.09.023.

2. Hogge W, Byrnes A, Lanasa M, et al. The clinical use of karyotyping spontaneous abortions. American Journal of Obstetrics and Gynecology. 2003; 189(2): 397-400, doi: 10.1067/s0002-9378(03)00700-2.

3. El Hachem H, Crepaux V, May-Panloup P, et al. Recurrent pregnancy loss: current perspectives. Int J Womens Health. 2017; 9: 331-345, doi: 10.2147/IJWH.S100817, indexed in Pubmed: 28553146.

4. DeFronzo RA, Ferrannini E. Insulin resistance. A multifaceted syndrome responsible for NIDDM, obesity, hypertension, dyslipidemia, and atherosclerotic cardiovascular disease. Diabetes Care. 1991; 14(3): 173-194, doi: 10.2337/diacare.14.3.173, indexed in Pubmed: 2044434.

5. Hooijschuur M, Ghossein-Doha C, Al-Nasiry S, et al. Maternal metabolic syndrome, preeclampsia, and small for gestational age infancy. American Journal of Obstetrics and Gynecology. 2015; 213(3): 370.e1-370.e7, doi: 10.1016/j.ajog.2015.05.045

6. Miyakis S, Lockshin MD, Atsumi T, et al. International consensus statement on an update of the classification criteria for definite antiphospholipid syndrome (APS). J Thromb Haemost. 2006; 4(2): 295-306, doi: 10.1111/j.1538-7836.2006.01753.x, indexed in Pubmed: 16420554.

7. Alberti KG, Eckel RH, Grundy SM, et al. International Diabetes Federation Task Force on Epidemiology and Prevention, Hational Heart, Lung, and Blood Institute, American Heart Association, World Heart Federation, International Atherosclerosis Society, International Association for the Study of Obesity. Harmonizing the metabolic syndrome: a joint interim statement of the International Diabetes Federation Task Force on Epidemiology and Prevention; National Heart, Lung, and Blood Institute; American Heart Association; World Heart Federation; International Atherosclerosis Society; and International Association for the Study of Obesity. Circulation. 2009; 120(16): 1640-1645, doi: 10.1161/CIRCULATIONAHA.109.192644, indexed in Pubmed: 19805654.

8. Kozan O, Oguz A, Abaci A, et al. Prevalence of the metabolic syndrome among Turkish adults. European Journal of Clinical Nutrition. 2006; 61 (4): 548-553, doi: 10.1038/sj.ejcn.1602554.

9. Soysal A, Demiral Y, Soysal D, et al. The prevalence of metabolic syndrome among young adults in Izmir, Turkey. Anadolu Kardiyol Derg. 2005; 5(3): 196-201, indexed in Pubmed: 16140651.

10. Jamwal S, Sharma S. Vascular endothelium dysfunction: a conservative target in metabolic disorders. Inflamm Res. 2018; 67(5): 391-405, doi: 10.1007/s00011-018-1129-8, indexed in Pubmed: 29372262.

11. Murphy M, Tayade C, Smith G. Evidence of inflammation and predisposition toward metabolic syndrome after pre-eclampsia. Pregnancy Hypertension: An International Journal of Women's Cardiovascular Health. 2015; 5(4): 354-358, doi: 10.1016/j.preghy.2015.09.007.

12. Carpenter MW. Gestational Diabetes, Pregnancy Hypertension, and Late Vascular Disease. Diabetes Care. 2007; 30(Supplement 2): S246-S250, doi: $10.2337 /$ dc07-s224.

13. Correction to: Systematic Review for the 2017 ACC/AHA/AAPA/ABC/ACPM/AGS/APhA/ASH/ASPC/NMA/PCNA Guideline for the Prevention, Detection, Evaluation, and Management of High Blood Pressure in Adults: A Report of the American College of Cardiology/American Heart Association Task Force on Clinical Practice Guidelines.Hypertension.2018;71(6):e145, doi:10.1161/HYP.0000000000000077, indexed in Pubmed: 29743248.

14. Ageno W, Prandoni $\mathrm{P}$, Romualdi $\mathrm{E}_{\text {, et }}$ al. The metabolic syndrome and the risk of venous thrombosis: a case-control study. JThromb Haemost. 2006; 4(9): 1914-1918, doi: 10.1111/j.1538-7836.2006.02132.x, indexed in Pubmed: 16848878.

15. Bartha J, González-Bugatto F, Fernández-Macías R, et al. Metabolic syndrome in normal and complicated pregnancies. European Journal of Obstetrics \& Gynecology and Reproductive Biology. 2008; 137(2): 178-184, doi: 10.1016/j.ejogrb.2007.06.011.

16. Mierzynski R, Poniedzialek-Czajkowska E, Kimber-Trojnar Z, et al. Anticoagulant therapy in pregnant patients with metabolic syndrome: a review. Curr Pharm Biotechnol. 2014; 15(1): 47-63, doi: 10.2174/138920101566 6140330194049, indexed in Pubmed: 24720594.

17. Clark $P$, Walker ID, Langhorne $P$, et al. Scottish Pregnancy Intervention Study (SPIN) collaborators. SPIN (Scottish Pregnancy Intervention) study: a multicenter, randomized controlled trial of low-molecular-weight heparin and low-dose aspirin in women with recurrent miscarriage. Blood. 2010; 115(21): 4162-4167, doi: 10.1182/blood-2010-01-267252, indexed in Pubmed: 20237316.

18. Skeith L, Rodger M. Anticoagulants to prevent recurrent placenta-mediated pregnancy complications: Is it time to put the needles away? Thrombosis Research. 2017; 151:S38-S42, doi: 10.1016/s0049-3848(17)30065-8. 